\title{
Meningkatkan Kinerja Mesin Extrude Hydron Menggunakan Metode Preventive Maintenance
}

\author{
Gerry Asprilla $^{1^{*}}$, Pamuji Agustiar ${ }^{2}$ \\ 1,2 Program Studi Teknik Mesin \\ Sekolah Tinggi Teknologi Muhammadiyah Cileungsi \\ Jl. Anggrek No.25, Perum. PTSC, Cileungsi, Bogor, Jawa Barat 16820 \\ *E-mail : Gerryasprilla@gmail.com, agustiarpamuji@gmail.com
}

\begin{abstract}
Abstrak. Efisiensi proses adalah suatu keharusan bagi perusahaan manufaktur di era kompetitif yang semakin ketat ini. Output produksi yg optimal bergantung salah satunya kepada bagaimana tingkat availability mesin dalam mendukung kegiatan produksi. PT. X adalah salah satu perusahaan manufaktur yg menggunakan mesin extruder yaitu proses pembentukan logam yang bertujuan untuk mereduksi atau mengecilkan penampang dengan cara menekan bahan logam melalui dies. Isu yang terjadi terkait dalam mempertahankan availability mesin dikarenakan tingkat downtime mesin yg cukup tinggi, selama periode Oktober 2019 yaitu mengalami 1 kali downtime dengan total waktu downtime 264,33 jam. Kerusakan komponen pada mesin produksi mengakibatkan penurunan performa mesin. Penelitian ini bertujuan untuk mengidentifikasi masalah yg terjadi dan menemukan akar masalahnya dan membuat formulasi untuk menanggulanginya. Temuan dari penelitian ini adalah dari kurangnya perawatan pada 4 komponen kiritis yang menjadi penyebab kerusakan pada subsistem mesin extrude hydron. Tim kemudian merumuskan program Preventive dan Predictive maintenance guna menanggulanginya. Pengembangan operator dalam hal operasional juga harus ditingkatkan, jika operator yang bertugas tidak handal, akan mempengaruhi kinerja mesin.
\end{abstract}

Kata kunci: Extrude Hydron Machine, Downtime, Perawatan preventif.

Abstract. Process efficiency is a must for manufacturing companies in this increasingly competitive competitive era. Optimal production output depends one of them on how the level of machine availability in supporting production activities. PT. $X$ is a manufacturing company that uses an extruder machine, which is a metal forming process that aims to reduce or reduce the cross section by pressing metal material through dies. The issue that occurred was related to maintaining machine availability due to the high level of engine downtime, during the October 2019 period, which experienced 1 downtime with a total downtime of 264.33 hours. Damage to components on the production machine results in a decrease in engine performance. This study aims to identify problems that occur and find the root of the problem and make formulations to overcome it. The findings of this study are the lack of maintenance on 4 critical components that cause damage to the extrude hydron engine subsystem. The team then formulated a Preventive \& Predictive maintenance gun program to overcome it. Operational development in terms of operations must also be improved, if the operator in charge is not reliable, it will affect the performance of the machine.

Keywords: Extrude Hydron Machine, Downtime, Preventive maintenance.

\section{PENDAHULUAN}

Efisiensi proses adalah suatu keharusan bagi perusahaan manufaktur di era kompetitif yang semakin ketat ini. Output produksi yang optimal bergantung salah satunya kepada bagaimana tingkat kehandalan mesin dalam mendukung kegiatan produksi. PT. $X$ adalah salah satu perusahaan manufaktur yang menggunakan mesin extruder untuk proses pembentukan logam yang bertujuan untuk mereduksi atau mengecilkan penampang dengan cara menekan bahan logam melalui dies. Isu yang terjadi terkait dalam mempertahankan kehandalan mesin dikarenakan tingkat downtime mesin yang cukup tinggi. Kerusakan komponen pada mesin produksi mengakibatkan penurunan performa mesin. Pada analisis [1] ini dilakukan pilot

JTTM : Jurnal Terapan Teknik Mesin is licensed under a Creative Commons AttributionNonCommercial 4.0 International License.

Meningkatkan Kinerja Mesin Extrude Hydron Menggunakan Metode Preventive Maintenance-Gerry Asprilla, Pamuji Agustiar 
Jurnal Terapan Teknik Mesin, Vol.1, No. 1, April 2020, 18 - 24

project terhadap mesin extrude di line 4. Dengan total downtime tertinggi selama periode Oktober 2019 mengalami 1 kali downtime dengan total waktu downtime 264,33 jam.

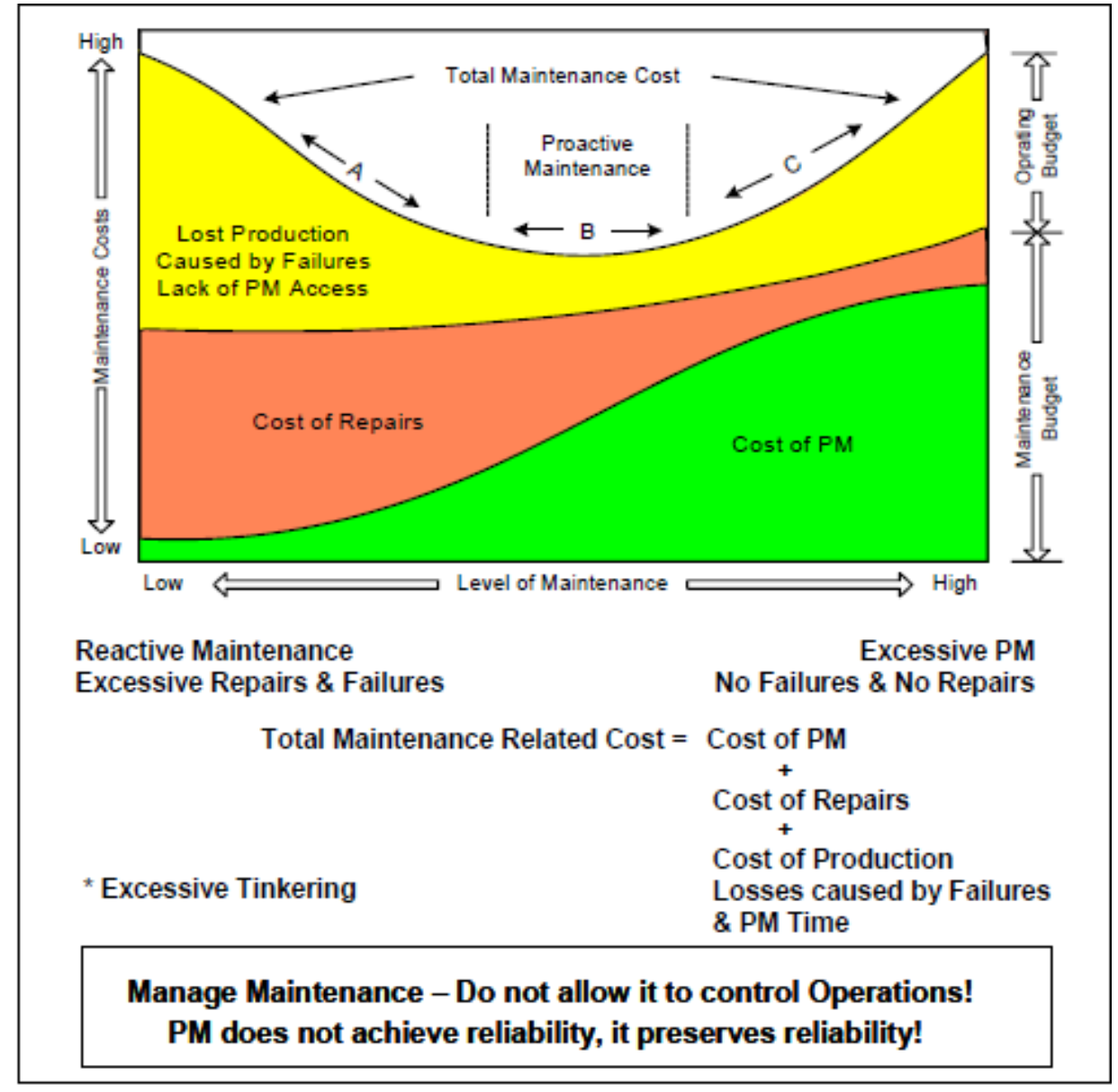

Gambar 1. Tantangan pemeliharaan (eksperimen terkendali).

Berdasarkan penafsiran terhadap buku dan penelitian terkait mesin extruder terdahulu umumnya isu terjadi karena kurangnya fokus pada analisis kekurangan yang terjadi dalam operasi pemeliharaan, dan tidak adanya prosedur untuk melaksanakannya [2]. Program pemeliharaan adalah untuk mencapai keseimbangan ekonomi yang benar antara biaya perawatan yang rendah dan "uptime" maksimum atau keandalan peralatan produksi. Menemukan keseimbangan ideal antara biaya dan waktu aktif adalah yang terbaik, karena sering ada jeda waktu antara sebab dan akibat; yaitu, dapat mengurangi pemeliharaan dan tidak melihat hasilnya dalam peningkatan waktu henti dan masalah lainnya sampai lama. Kemudian ketika yang paling tidak mengharapkannya, gelombang masalah muncul, menghasilkan gangguan, pengeluaran yang tidak direncanakan, dan membuat marah pelanggan [3]. Pemeliharaan terjadwal menjaga aset tetap berjalan, menghemat biaya yang tidak direncanakan, menyederhanakan manajemen teknisi dan keterampilan mereka, dan meningkatkan OEE [4]. Kerusakan komponen pada mesin produksi mengakibatkan penurunan performa mesin, Penelitian ini bertujuan untuk mengidentifikasi masalah yang terjadi dan menemukan akar masalahnya dan membuat formulasi untuk menanggulanginya.

JTTM : Jurnal Terapan Teknik Mesin is licensed under a Creative Commons AttributionNonCommercial 4.0 International License.

Meningkatkan Kinerja Mesin Extrude Hydron Menggunakan Metode Preventive Maintenance-Gerry Asprilla, Pamuji Agustiar 
Jurnal Terapan Teknik Mesin, Vol.1, No. 1, April 2020, 18 - 24

\section{METODE}

Alur penelitian ini dimulai dari :

1. Mengidentifikasi masalah yang terjadi di lapangan, terutama berapa sering kerusakan dalam 1 bulan sampai 1 tahun.

2. Membandingkan kinerja pada mesin yang akan dilakukan penelitian dengan cara pengecekan visual pada kondisi mesin yang masih normal operasi.

3. Analisa kerusakan dan Pemeriksaan vakum pada suplai udara dan pergerakan piston pada kompresor. Pengecekan data perbaikan untuk mengetahui trend kerusakan maupun perbaikan yang telah dilakukan.

4. Analisa kerusakan adalah untuk mengetahui akar penyebab dari kerusakan yang terjadi, agar meminimalisasi kerusakan mesin extruder.

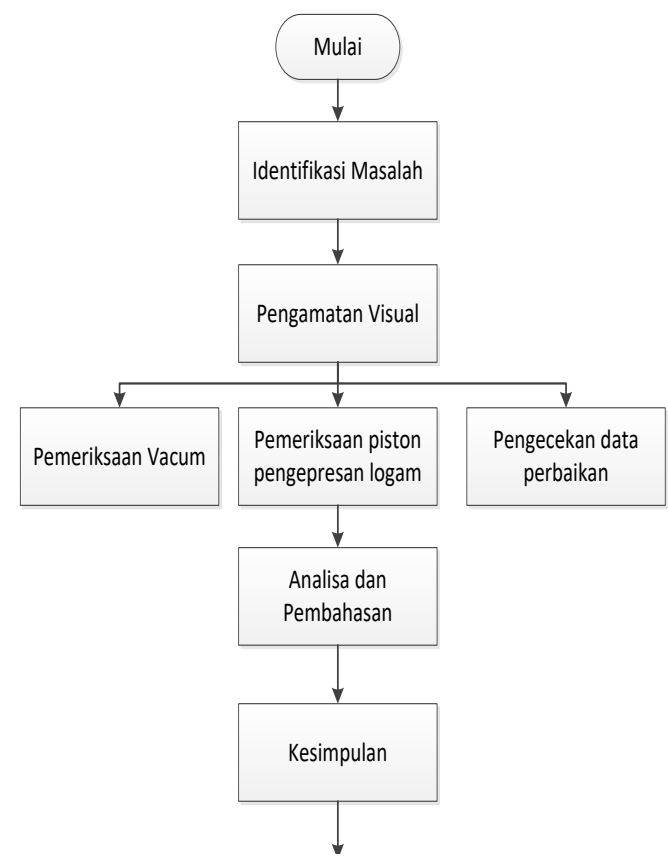

Gambar 2. Alur penelitian.

\section{HASIL DAN PEMBAHASAN}

3.1 History Maintenance Mesin Extrude Hydron.

Data history maintenance dan waktu perbaikan korektif komponen pada mesin extrude hydron selama periode oktober 2019 ditampilkan pada gambar 3 dan 4. Pada gambar 4, diketahui komponen yang paling sering mengalami kerusakan dari tiap-tiap subsistem mesin extrude hydron yaitu filter vakum, selang vakum, dan digital Indikator vakum. Diketahui dari tiap-tiap subsistem mesin extrude hydron yaitu sensor otomatis (Limit Switch Piston, Limit Switch Silinder Pneumatic).

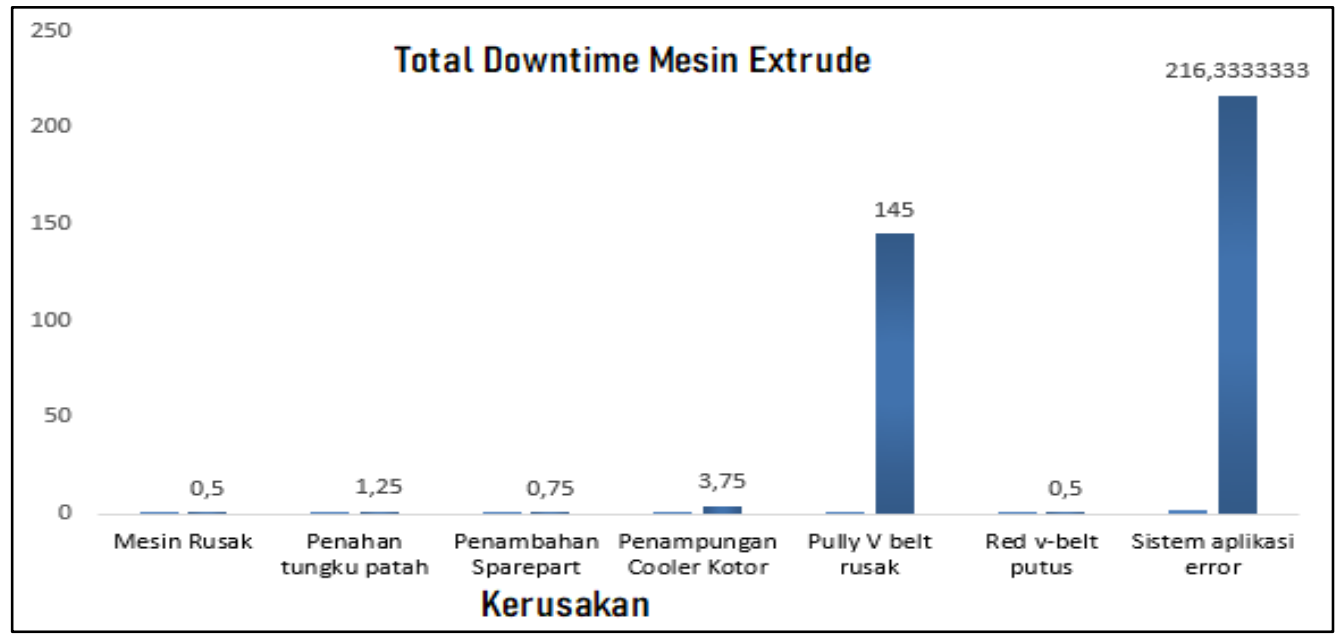

Gambar 3. Grafik total downtime mesin extrude hydron

JTTM : Jurnal Terapan Teknik Mesin is licensed under a Creative Commons AttributionNonCommercial 4.0 International License.

Meningkatkan Kinerja Mesin Extrude Hydron Menggunakan Metode Preventive Maintenance-Gerry Asprilla, Pamuji Agustiar 
Jurnal Terapan Teknik Mesin, Vol.1, No. 1, April 2020, 18 - 24

3.2 Review Catatan Downtime Mesin Extrude Hydron.

Dari data history perbaikan mesin extrude hydron menunjukkan trending kerusakan pada mesin line 4. Dimana mesin ini sering mengalami kerusakan, dengan kondisi tersebut mesin extrude hydron tidak bisa dioperasikan sehingga mengganggu produktifitas. Berikut ini adalah grafik downtime pada mesin extrude hydron di PT. X:

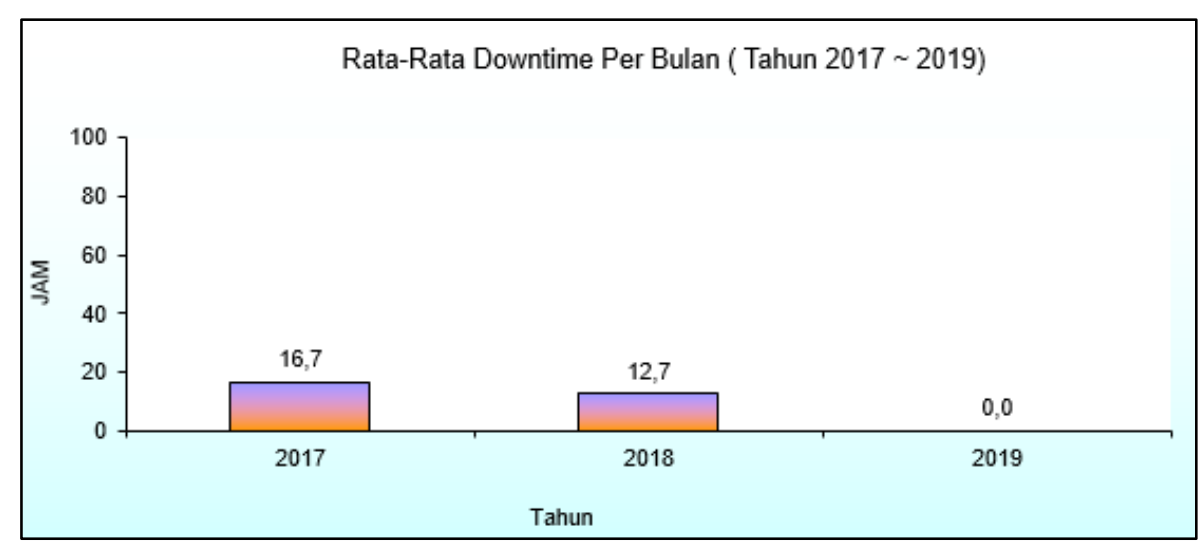

Gambar 4. Grafik downtime

Dari hasil detail ketidaksesuaian downtime tidak terencana dalam 1 tahun tidak tercapai. Dan hasil yang didapatkan adalah 10 hari kerja (07-18 Oktober 2019).

\subsection{Tindakan Penerapan Preventive Maintenance [5] dan Predictive Maintenance}

Hasil kajian terhadap data-data total downtime yang dikumpulkan dari penelitian ini dapat dilihat pada gambar 2. Yang memberikan total downtime tertinggi dari kerusakan mesin extrude hydron dimana:

1) Downtime yang paling tinggi adalah sistem aplikasi error 216 Jam. Dimana Untuk melakukan perbaikan tersebut harus dilakukan oleh manufaktur mesin, hal ini diluar jangkauan pihak peneliti, dan tindakan yang dilakukan adalah mencoba menghubungi pihak produsen mesin dalam menanggulanginya. Hal ini diprediksi akan membutuhkan waktu lama dalam mereset sistem aplikasi

2) Downtime tertinggi kedua adalah kerusakan $V$ belt 145 jam. Dimana dari Dari pengecekan tim peneliti dilapangan dan berdasarkan wawancara diketahui bahwa hal ini diakibatkan perawatan yang tidak tepat pada 4 komponen kritis yang menjadi penyebab kerusakan pada subsistem mesin extrude hydron yaitu filter vakum, selang vakum, digital indikator vakum, sensor otomatis (Limit Switch Piston, Limit Switch Silinder Pneumatic).

Tim peneliti membuat program PM (preventive dan predictive) secara berkala meskipun diperlakukan sebagai elemen yang terpisah, pemeliharaan preventif atau prediktif [6], rekayasa keandalan, riwayat peralatan, fungsional, dan jaminan kualitas sangat mendukung masing-masing dengan yang lain. Keberhasilan program pemeliharaan preventif [6] atau prediktif tergantung pada keberadaan tiga elemen lainnya. Sementara perencanaan dan penjadwalan memastikan pemanfaatan sumber daya yang efektif untuk mempertahankan program pemeliharaan proaktif yang telah mapan [7], tujuan dari penerapan PM ini [8]:

1. Penurunan kerusakan komponen.

2. Lebih sedikit gangguan darurat dan darurat untuk operasi karena kerusakan peralatan.

JTTM : Jurnal Terapan Teknik Mesin is licensed under a Creative Commons AttributionNonCommercial 4.0 International License.

Meningkatkan Kinerja Mesin Extrude Hydron Menggunakan Metode Preventive Maintenance-Gerry Asprilla, Pamuji Agustiar 
Jurnal Terapan Teknik Mesin, Vol.1, No. 1, April 2020, 18 - 24

3. Kinerja karyawan meningkat.

4. Pengurangan total tenaga kerja yang dibutuhkan untuk memelihara fasilitas dalam kondisi yang disyaratkan.

5. Pengurangan terkendali dalam inventaris bahan dan suku cadang.

6. Peningkatan volume pekerjaan yang dapat direncanakan dan dijadwalkan secara efektif, dan penurunan prioritas tinggi, pekerjaan yang terjadi secara acak dan tidak terjadwal.

7. Meminimalisasikan gagal produk.

Dan berikut ini gambar atau contoh perawatan pada mesin Extrude Hydron di PT. X.

a. Pemeriksaan vakum pressure agar pengepresan logam berjalan dengan baik dan sesuai prosedur proses produksi.

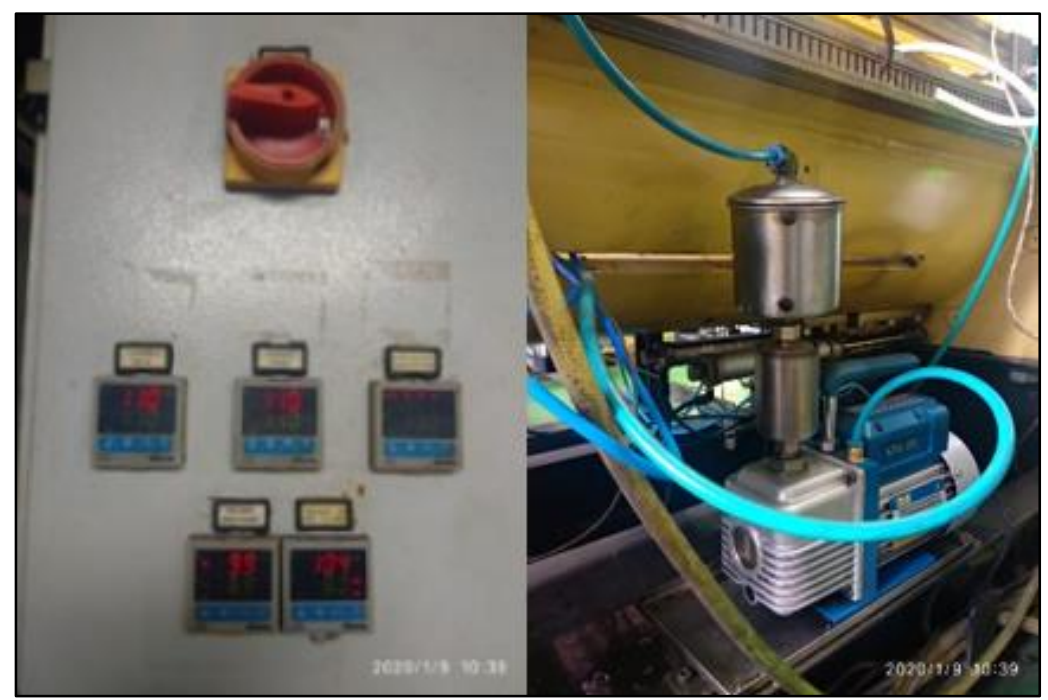

Gambar 2. Panel kontrol dan vakum pressure.

b. Pemeriksaan piston pada mesin extrude hydron agar kondisi piston tetap prima dan tidak mengganggu proses produksi.

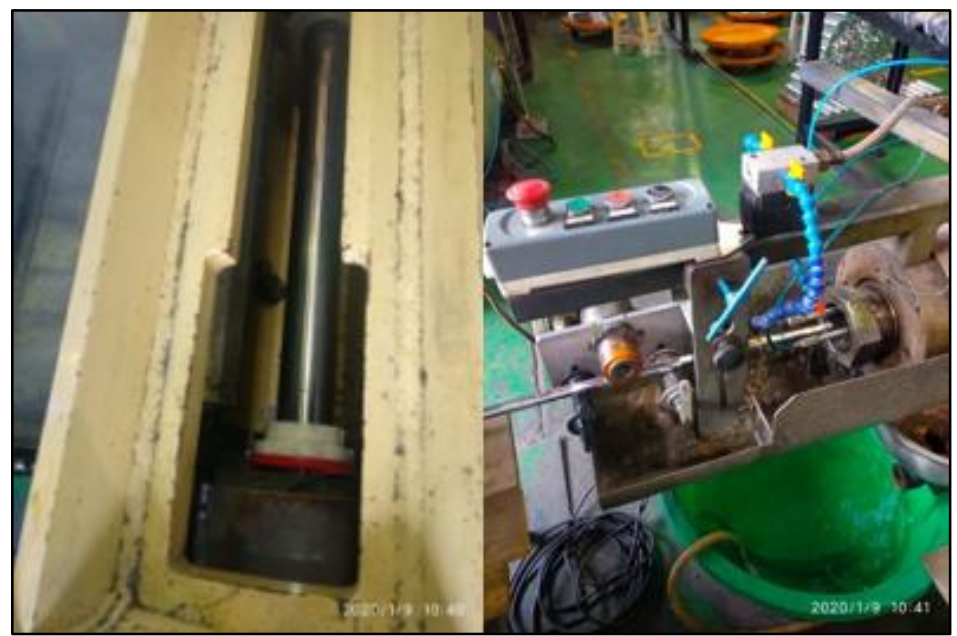

Gambar 3. Piston.

JTTM : Jurnal Terapan Teknik Mesin is licensed under a Creative Commons AttributionNonCommercial 4.0 International License.

Meningkatkan Kinerja Mesin Extrude Hydron Menggunakan Metode Preventive Maintenance-Gerry Asprilla, Pamuji Agustiar 
Jurnal Terapan Teknik Mesin, Vol.1, No. 1, April 2020, 18 - 24

c. Pengecekan Tabel preventif vakum pada mesin extrude hydron.

Tabel 1. Preventif maintenance pada mesin extrude hydron.

\begin{tabular}{|c|c|c|c|}
\hline NO & PART/KOMPONEN & $\begin{array}{c}\text { YANG } \\
\text { DIPERIKSA }\end{array}$ & STANDART \\
\hline \multirow{2}{*}{1} & \multirow{2}{*}{ Box panel mesin } & $\begin{array}{l}\text { Selector } \\
\text { switch }\end{array}$ & $\begin{array}{l}\text { On/Off fungsi normal (jika selector } \\
\text { switch pakai lampu didalamnya, lampu } \\
\text { harus nyala) }\end{array}$ \\
\hline & & Lampu & $\begin{array}{l}\text { Nyala sesuai fungsinya (ON, Alarm, } \\
\text { Emergency,dll) }\end{array}$ \\
\hline \multirow{4}{*}{2} & \multirow{4}{*}{ Pompa vakum } & Filter vakum & $\begin{array}{l}\text { Bersih tidak ada kotoran serbuk timah } \\
\text { (kotoran timah yang berada di filter } \\
\text { diambil pakai pinset, jika ada serpihan } \\
\text { timah di filter yang susah diambil sedot } \\
\text { pakai vakum cleaner) }\end{array}$ \\
\hline & & Batas level oli & $\begin{array}{l}\text { Saat kondisi OFF oli dibatas level } \\
\text { maximum (jika sampai batas bawah oli } \\
\text { ditambah) }\end{array}$ \\
\hline & & Selang vakum & $\begin{array}{l}\text { Dengan ditembak pakai angin atau air } \\
\text { duster gun setelah selang dilepas } \\
\text { dipastikan tidak ada kotoran,jika sudah } \\
\text { kelihatan gosong mengecil pada ujung } \\
\text { selang,selang harus diganti }\end{array}$ \\
\hline & & $\begin{array}{l}\text { Digital } \\
\text { Indikator } \\
\text { vakum } \\
\end{array}$ & $\begin{array}{l}\text { Kondisi normal indikator menunjukan - } \\
90 \sim 99\end{array}$ \\
\hline 3 & $\begin{array}{l}\text { Penampungan air } \\
\text { sirkulasi }\end{array}$ & Batas level air & $\begin{array}{l}\text { Kondisi normal radar masih berfungsi } \\
\text { baik,jika air kurang radar tidak bekerja } \\
\text { jadi pompa nyala terus (tambahkan air di } \\
\text { bak penampungan) }\end{array}$ \\
\hline 4 & Kompresor & $\begin{array}{l}\text { Endapan air } \\
\text { dalam tabung }\end{array}$ & $\begin{array}{l}\text { Saat kran ditabung dibuka tidak ada } \\
\text { air/kosong (jika kran dibuka ada } \\
\text { air,buang air sampai habis) }\end{array}$ \\
\hline
\end{tabular}

\section{SIMPULAN}

Dari hasil penelitian ini dapat disimpulkan: Dari pengecekan perawatan, terdapat 4 komponen kritis yang menjadi penyebab kerusakan pada subsistem mesin extrude hydron yaitu filter vacum, selang vacum, digital indikator vacum, sensor otomatis (Limit Switch Piston, Limit Switch Silinder Pneumatic). Sistem perawatan yang dilakukan pada mesin Extrude Hydron adalah secara mingguan dan bulanan. Pengecekan secara visual sebelum mengoperasikan adalah langkah meminimalkan kerusakan. Pemahaman operator yang bertugas akan menentukan meningkatkan kehandalan mesin produksi. Kerusakan pada mesin extrude hydron bisa diminimalisasi dengan cara mengevaluasi kerusakan yang terjadi. Pengembangan operator dalam hal operasional juga harus ditingkatkan, jika operator yang bertugas tidak handal, akan mempengaruhi kinerja mesin.

JTTM : Jurnal Terapan Teknik Mesin is licensed under a Creative Commons AttributionNonCommercial 4.0 International License.

Meningkatkan Kinerja Mesin Extrude Hydron Menggunakan Metode Preventive Maintenance-Gerry Asprilla, Pamuji Agustiar 
Jurnal Terapan Teknik Mesin, Vol.1, No. 1, April 2020, $18-24$

\section{DAFTAR PUSTAKA}

[1] E. O. Ogur and Mburu, "Failure Analysis of a bar Soap Extrusion Machine," J. Eng. Res. Appl. www.ijera.com, vol. 3, no. February, pp. 624-629, 2015.

[2] M. P. Pérez and Á. T. P. Rodríguez, "Proposal of procedure for maintenance management in plastics processing factories of Cuba," Proc. Int. Conf. Ind. Eng. Oper. Manag., vol. 2018, no. JUL, pp. 2823-2834, 2018.

[3] A. Kennedy and K. Eurotech, "Managing Extrusion Plant Maintenance," pp. 425-431.

[4] " 5 best practices to improve OEE with condition-based monitoring On average ,."

[5] D. Manesi and A. P. Kupang, "PENERAPAN PREVENTIVE MAINTENANCE UNTUK MENINGKATKAN KINERJA FASILITAS PRAKTIK LABORATORIUM PRODI PENDIDIKAN TEKNIK MESIN UNDANA Damianus Manesi Program Studi Pendidikan Teknik mesi ...," no. March, 2018.

[6] C. Ferrarese and F. Piazza, "Preventive and Predictive Maintenance," J. Alzheimer's Dis., vol. 29, no. SUPPL. 1, pp. 23-24, 2012.

[7] S. Taewang, "The Improvement of Maintenance System and Documentation," pp. 111, 2016.

[8] "Comprehensive Maintenance Management."

JTTM : Jurnal Terapan Teknik Mesin is licensed under a Creative Commons AttributionNonCommercial 4.0 International License.

Meningkatkan Kinerja Mesin Extrude Hydron Menggunakan Metode Preventive Maintenance-Gerry Asprilla, Pamuji Agustiar 